\title{
Chemoradiotherapy for esophageal cancer before or after surgery: It is not just a matter of time
}

\author{
Simon R. Turner, MD, and Daniela Molena, MD
}

\footnotetext{
From the Thoracic Surgery Service, Memorial Sloan Kettering Cancer Center, New York, NY.

Disclosures: Authors have nothing to disclose with regard to commercial support.

Received for publication April 11, 2017; accepted for publication April 22, 2017; available ahead of print May 17. 2017.

Address for reprints: Daniela Molena, MD, Thoracic Surgery Department, Memorial Sloan Kettering Cancer Center, 1275 York Ave, New York, NY 10065 (E-mail: molenad@mskcc.org).

J Thorac Cardiovasc Surg 2017;154:730-1

$0022-5223 / \$ 36.00$

Copyright (c) 2017 by The American Association for Thoracic Surgery

http://dx.doi.org/10.1016/j.jtcvs.2017.04.056
}

There is little debate that optimal therapy for locally advanced esophageal cancer involves a multimodality approach. Both neoadjuvant and adjuvant chemoradiation have been shown to improve survival. ${ }^{1,2}$ The two have not been definitively compared, however, in a prospective, randomized trial. Accordingly, there continues to be debate about the optimal timing of chemoradiation. Neoadjuvant therapy improves complete resection rates and leads to pathologic complete response in almost half of the patients. Moreover, it is well tolerated by patients and often improves dysphagia. After the success of the ChemoRadiotherapy for Oesophageal Cancer Followed by Surgery Study (CROSS) trial, neoadjuvant chemoradiation has become standard in many parts of the world. ${ }^{1}$ Adjuvant therapy is difficult for the patients to endure after major surgery, and therapy is often not fully delivered. The value of radiation is questionable unless there are positive margins, and there is potential for longterm damage to the interposed conduit. Adjuvant therapy does have the advantage of avoiding overtreating patients with inaccurately staged early disease, who may have worse outcomes with a multimodality approach.

We therefore commend Hsu and colleagues ${ }^{4}$ for their retrospective study in this issue of the Journal comparing patients with esophageal squamous cell cancer (SCC) in the Taiwan Cancer Registry receiving neoadjuvant versus adjuvant chemoradiation. No differences were found in terms of overall survival, disease-free survival, or recurrence. Timing of therapy was not predictive of survival. Hsu and colleagues ${ }^{4}$ conclude that their results "suggested that there is not a substantial difference" between neoadjuvant and adjuvant therapy. There are some limitations of this study that should be noted, however, which may account for the inability to detect differences in outcomes.

Although propensity matching was used to control for differences in demographic characteristics and some tumor factors, other important pieces of information, including patient comorbidities, were not available from

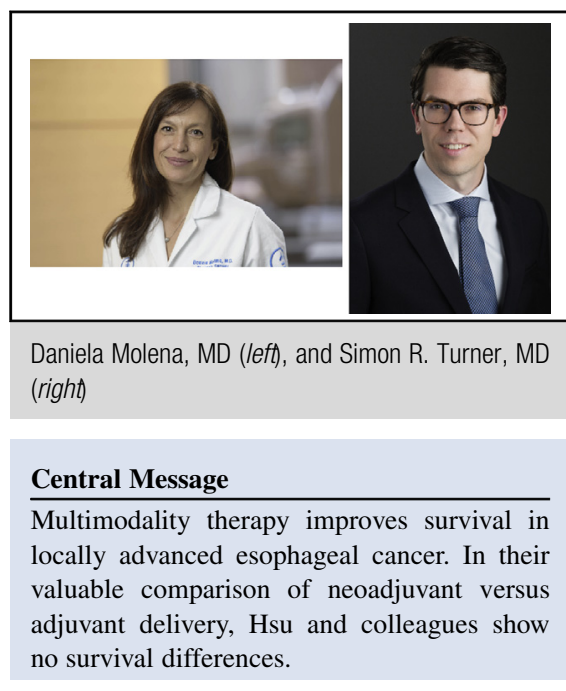

See Article page 732

the database used and were therefore unknown and unaccounted for. Patients receiving adjuvant therapy must have been in good condition after surgery to be candidates, whereas an unknown number receiving neoadjuvant therapy may have had significant morbidities and delayed mortality. Furthermore, patients in the neoadjuvant group had a higher incidence of stage III, cT3/4, and N+ tumors, and they had larger tumors. In addition, center- or physician-specific biases toward one approach over the other may also have existed and may confound the results.

The results of patients in this neoadjuvant group, who received fluorouracil and cisplatin, compare poorly with the success of the CROSS trial in which patients received carboplatin and paclitaxel. In the population of Hsu and colleagues, ${ }^{4} 28.6 \%$ had pathologic complete response, compared with $49 \%$ among patients with SCC in the CROSS trial. This may help explain why the 3 -year survival in the neoadjuvant group was only $44.0 \%$, much lower than the CROSS 3-year survival for SCC of greater than $60 \%$. If the outcomes had approximated those seen in the CROSS trial, there would almost certainly have been statistically significant differences found. Indeed, there was a nonsignificant trend toward improved survivals in the neoadjuvant arm, with disease-free survival nearly meeting significance.

The question of whether neoadjuvant or adjuvant chemoradiation is equivalent for esophageal SCC is an important one. This study well highlights this issue and hopefully will stimulate further research. 


\section{References}

1. van Hagen P, Hulshof MC, van Lanschot JJ, Steyerberg EW, van Berge Henegouwen MI, Wijnhoven BP, et al; CROSS Group. Preoperative chemoradiotherapy for esophageal or junctional cancer. N Engl J Med. 2012;366:2074-84.

2. Bédard EL, Inculet RI, Malthaner RA, Brecevic E, Vincent M, Dar R. The role of surgery and postoperative chemoradiation therapy in patients with lymph node positive esophageal carcinoma. Cancer. 2001;91:2423-30.

3. Mariette C, Dahan L, Mornex F, Maillard E, Thomas PA, Meunier B, et al. Surgery alone versus chemoradiotherapy followed by surgery for stage I and II esophageal cancer: final analysis of randomized controlled phase III trial FFCD 9901. J Clin Oncol. 2014;32:2416-22.

4. Hsu PK, Chen HS, Liu CC, Huang CS, Hsieh CC, Hsu HS, et al. Pre- versus postoperative chemoradiotherapy for locally advanced esophageal squamous cell carcinoma. J Thorac Cardiavasc Surg. 2017;154:732-40. 